\title{
XLIX. On the distance between the poles of a magnet, the coefficients of temperature and induction, and on the determination of moments of inertia by means of bifilar suspension
}

\section{F. Kohlrausch}

To cite this article: F. Kohlrausch (1884) XLIX. On the distance between the poles of a magnet, the coefficients of temperature and induction, and on the determination of moments of inertia by means of bifilar suspension, Philosophical Magazine Series 5, 18:114, 446-454, DOI: 10.1080/14786448408627618

To link to this article: http://dx.doi.org/10.1080/14786448408627618

\section{曲 Published online: 29 Apr 2009.}

Submit your article to this journal ¿

\section{Article views: 2}


Zine Wires.

\begin{tabular}{|c|c|c|c|c|}
\hline & \multicolumn{2}{|c|}{ No. 5 . } & \multicolumn{2}{|c|}{ No. 6 . } \\
\hline & Resistance. & Difference. & Resistance. & Difference. \\
\hline 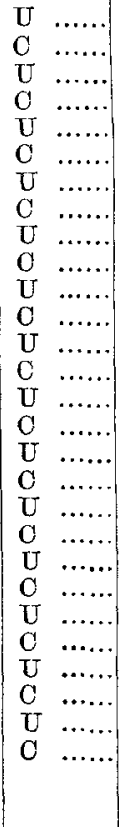 & $\begin{array}{c}-14063 \\
077 \\
095 \\
104 \\
128 \\
135 \\
146 \\
149 \\
160 \\
164 \\
173 \\
178 \\
186 \\
190 \\
200 \\
205 \\
212 \\
219 \\
227 \\
239 \\
244 \\
257 \\
261 \\
270 \\
273 \\
278 \\
278 \\
295 \\
\\
\text { Wir }\end{array}$ & $\begin{array}{l}+.00014 \\
+.00018 \\
+.00009 \\
+.00024 \\
+\cdot 00007 \\
+\cdot 00011 \\
+.00003 \\
+.00011 \\
+.00004 \\
+.00009 \\
+.00005 \\
+\cdot 00008 \\
+\cdot 00004 \\
+.00010 \\
+.00005 \\
+.00007 \\
+.00007 \\
+.00008 \\
+.00012 \\
+.00005 \\
+.00013 \\
+.00004 \\
+.00009 \\
+.00002 \\
+.00006 \\
+\ldots \ldots \\
+.00017 \\
\end{array}$ & $\begin{array}{r}\cdot 14038 \\
065 \\
090 \\
087 \\
119 \\
117 \\
138 \\
138 \\
152 \\
149 \\
16 \pm \\
163 \\
178 \\
180 \\
191 \\
193 \\
205 \\
208 \\
218 \\
221 \\
230 \\
235 \\
215 \\
251 \\
270 \\
288\end{array}$ & 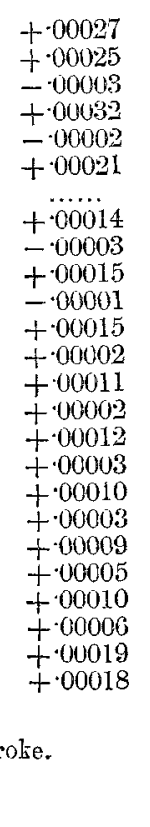 \\
\hline
\end{tabular}

XLIX. On the Distance between the Poles of a Magnet, the Coefficients of Temperature and Induction, and on the Determination of Moments of Inertia by means of Bifilar Suspension. By F. KoHlrausch*.

W HENFVER a magnet forms the object or means of any measurement, there are especially the following properties to be taken into account. Besides its magnetic moment, the changes in the same with temperature and with the position in the magnetic field play an important part, the distribution of magnetism in the bar, and, as a first approximation, the distance apart of the poles of the magnet is of importance ; and the moment of inertia of the heary mass has to be taken into account in all the usual methods of observation.

* Translated from Weidemann's Annalen, Bd, xxii. p. 411. 
I take the present opportunity of communicating some observations and experiments upon each of these four magnitudes.

The results of the first part of the investigation, undertaken conjointly with Mr. W. Hallock, will appear shortly in detail.

\section{On the Distance Apart of the Poles of Magnets. By W.} Hallock and F. Kohlrausch*.

\section{On the Increase and Decrease in Magnetic Moment produced by Small Forces.}

We discuss here a single point, but a fundamental point in the doctrine of induced magnetism. If we expose a steel magnet to the action of feeble forces by which its magnetism is either strengthened or weakened, the question arises whether the increase and decrease in strength are of equal or of different magnitude. Lamontt has occupied himself with this inquiry in his extended magnetic researches, and found that the enfeeblement takes place more easily than the reinforcement, and about in the proportion $4: 3$; and this view seems to have been partially accepted by those $\ddagger$ who bave occupied themselves with the subject. No thorough experimental investigation, however, appears to exist, and yet it is a subject of the greatest importance in the more exact magnetic and electrical measurements. Wild considers the determination of the coefficient of induction as one of the chief difficulties in the measurement of the intensity of terrestrial magnetism, and, to avoid it, even proposes $\S$ to bring the oscillating magnet into a position at right angles to the meridian by means of a bifilar suspension.

Whilst it must be admitted that there is, in fact, a certain difficulty in the determination of the two different coefficients, yet this is much lessened if we have simply to determine their sum according to the method of induction-currents given by Weber\|. If we have established a nearly constant ratio between the coefficients, we of course need only to know their sum.

* A translation of this section was given among the short notices in our last Number, p. 390.

$\dagger$ Erdmagnetismus, p. 149 (1849).

+ Compare (e. g.)Wild, Rep.d. Meteor. d. K. Acad. za Petersb. viii. No.7, p. 61 (1883), where it is mentioned that some observers, amongst them the author, have made no distinction between the coefficient of increase and that of decrease.

$\$$ Wild, loc. cit. pp. $73 \& 43$.

if Alh. d. Gött. Ges. d. Wiss. vi. p. 65 of reprint, 1855. I cannot see that the method suffers from complication, as H. Wild thinks. The accuracy required here at least is to be obtained with very simple apparatus. 


\section{Prof. F. Kohlrausch on the Increase and Decrease}

It has always appeared to me most probable that this relation must exist, but not in the way assumed by Lamont, but simply as an equality. Lamont's experiments do not seem to be sufficient to justify the view originally taken by him. Later, Lamont appears* to return to the former view without expressly saying so. He refers only briefly to some experiments "previously prablished" by him, but does not mention their result again. On the contrary, he calculates as if both coefficients were of equal magnitude for very small forces, and speaks of this as the generally accepted view.

This latter view is indeed, à priori, the most probable, for it corresponds to the law of permanency.

The analogy, employed by Lamont, that a distorted elastic body is more easily caused to return to its natural form than to recede further from it, cannot be considered as of much force. This fact of molecular mechanics is no doubt true for persistent alteration of form. The limit of elasticity of a bent body is, we know, greater outwardly than inwardly ; and so, of conrse, a magnet will in general behare towards forces which are sufficiently great to cause a permanent alteration in its magnetism. But we are not now concerned with that. The change in magnetic moment depending upon change in position relative to the earth is to be compared to elastic changes in form, and for these there is no doubt that the modulus of elasticity is of equal magnitude in both directions.

I have abundantly convinced myself of the correctness of both of these assertions. A magret which had been exposed some $80(00$ times to a wealsening force of the magnitude of the earth's horizontal magnetism $(0.2$ centimetre-grammeunit) showed still the same magnetism as before to within $\overline{2}{ }_{\overline{0}}^{1} \overline{0} 0$. Aud, as far as the modulus of elasticity is concerned, I found this the same in both directions in a soft-steel rod which had been just before much bent. I have endeavoured, with the important assistance derived from the observations of M. Kreichgauer, to decide this question in the following manner.

First I employed Weber's method of currents induced in a rotated spiral by the varying magnetism, emploring only rotations of $90^{\circ}$; viz. first, from the east and west position of the magnet into the normal position (north pole towards the north), and, secondly, into the reversed position (north pole towards the south). The deflections of the galvanometer-needle in the two cases were found to be perceptibly equal.

A difference of less than 1 per cent. in favour of the coefficient of increase is easily accounted for by a small error in the adjustment of the spiral.

* Handb. d. Magnetism. p. 371 (1867). 
Weber's method becomes more convenient and more exact if, instead of reversing the magnet and spiral with reference to the earth's magnetism, we reverse a magnetic force with reference to the spiral and the magnet in the spiral. For this purpose the induction-spiral was further wound with 280 turns of wire, forming a coil of 5 centim. diameter and a total length of 39 centim., through which a current was passed, producing within the spiral a magnetic field of about $0 \cdot 2$ C.C.S.S. unit, and thus of about the same strength as the earth's horizontal magnetism. This current was made or interrupted so as to increase or to diminish the magnetism of the bar. Momentary currents were thus induced in the inner spiral, which were measured by the method of nultiplication. Moreover, the part of the induced current resulting from the magnetizing current itself could be compensated by means of a second duplicate spiral, which is an advantage of this electromagnetic method. A similar arrangement has already been described by Töpler and Von Eitingshausen*. Local disturbances are eliminuted by reversal of the current and magnet.

In order to infer the induced magnetism from the deflections of the galvanometer, a small magnet of known moment was employed, by the use of which experiments according to the method of multiplication could be made by introducing the magnet into the spiral and withdrawing it.

The steel bars were examined in various conditions of hardness and intensity of magnetization, as detailed in the first coluinn of the following Table. The mass $m$ of the bars is given in grammes, the magnetic moment in centimetre-gramme units, ind under $s$ the specific magnetism $\frac{M}{m}$ or the magnetic
moment per gramme of steel.

Lastly, under $+\Delta s$ and $-\Delta s$ are given the specific induction constants; so that the numbers denote the change in specific magnetism ; in other words, the increase or decrease in the magnetic moment of the unit of mass ( $1 \mathrm{gr}$.) which is produced by the unit of magnetizing or demagnetizing force $\left(\mathrm{gr} \cdot \mathrm{o}^{\frac{1}{2}} \mathrm{~cm} \cdot \mathrm{e}^{-\frac{1}{2}} \mathrm{sec}^{-1}\right)$.

By way of explanation, it may be observed that the number $\Delta s$ represents nearly the change in specific magnetism produced in our latitudes by reversing the bar in the direction of the dip-needle. About the fifth part is the "magnetism of position "produced in $1 \mathrm{gr}$. in our latitude by the earth's horizontal magnetism $\uparrow$.

* Pogg. Ann. clx. p. 1 (187\%).

$\uparrow$ Multiplied by $7 \cdot($ (the density of steel) the numbers $s$ or $\Delta s$ give the specific magnetism or induction-constant (as the case may be) referred to unit volumes, which latter, as Herwig has remarlied, represent absolute numbers, and are thus independent of the units employed. 


\begin{tabular}{|c|c|c|c|c|}
\hline & $m$. & M. & $s=\frac{\mathbf{M}}{m}$. & $+\Delta s \quad-\Delta s$ \\
\hline & & $\operatorname{cm}^{\frac{5}{2}} \mathrm{~g}^{\frac{1}{2}}$ & $\mathrm{~cm}^{\frac{5}{2}}$ & $\mathrm{~cm}^{3}$. \\
\hline $\begin{array}{l}\text { Oplinder, } 16 \mathrm{~cm} . \text { long, } 1.5 \mathrm{~cm} . \text { thick, } \\
\text { hard } \ldots \ldots \ldots \ldots \ldots \ldots \ldots \ldots \ldots \ldots\end{array}$ & $\begin{array}{l}\mathrm{g} . \\
216\end{array}$ & seo & $\overline{g^{\frac{1}{2}} \sec }$ & $\mathrm{g}$ \\
\hline Witto, magnetized a year ago...... & ... & 4200 & 20 & $+0.202-0.201$ \\
\hline Ditto, newly magnetized............. & & 6200 & 29 & $+0.218-0.214$ \\
\hline $\begin{array}{r}\text { Ditto, often magnetized and heated } \\
\text { for a long time } . . . \ldots \ldots \ldots \ldots \ldots \ldots \ldots\end{array}$ & $\cdots$ & 5000 & 23 & $+0.216-0.215$ \\
\hline $\begin{array}{l}\text { Hollow cylinder } 16 \mathrm{~cm} \text {. long, in } \\
\text { ternal and external diameter } 1 \cdot 2 \\
\text { and } 1.6 \mathrm{~cm} \text {. respectively................. }\end{array}$ & 109 & & & \\
\hline $\begin{array}{l}\text { Ditto, magnetized and heated a } \\
\text { year ago } \ldots \ldots \ldots \ldots \ldots \ldots \ldots \ldots \ldots\end{array}$ & $\cdots$ & 3500 & 32 & $+0.261-0.265$ \\
\hline Ditto, newly magnetized............... & & 4200 & 38 & $+0.261-0.264$ \\
\hline $\begin{array}{l}\text { Parallelopiped } 18 \times 1.5 \times 0.5 \mathrm{~cm} \text {. } \\
\text { Ditto soft unmagnetized }\end{array}$ & 114 & & & \\
\hline $\begin{array}{l}\text { Ditto, soft, magnetized } . . . . \\
\text { Ditu }\end{array}$ & $\begin{array}{l}\cdots \\
. .\end{array}$ & 940 & $8 \cdot 3$ & $+0 \cdot \frac{ \pm 0459}{447}-0.449$ \\
\hline Ditto, hard, unmagnetized. & “. & 0 & 0 & \pm 0335 \\
\hline Ditto, hard, magnetized ............ & & 3600 & 32 & $+0.308-0 \cdot 305$ \\
\hline Parallelopiped $18 \times 1.7 \times 0.6 \mathrm{~cm}$ & 144 & & & \\
\hline Ditto, sof & $\ldots$ & 0 & 0 & \pm 0.490 \\
\hline Ditto, soft, magnetized ...... & $\ldots$ & 1230 & $8 \cdot 6$ & $+0.457-0.465$ \\
\hline Ditto, hard, unmagnetized ... & $\ldots$ & 0 & 0 & \pm 0.341 \\
\hline Ditto, hard, magnetized ............. & $\ldots$ & 3900 & 27 & $+0.303-0.304$ \\
\hline
\end{tabular}

There is no decided difference in any one of these numbers betwecn the coefficient $+\Delta s$ of increase of strength and the coefficient of decrease in strength $-\Delta s$.

The small differences of irregular sign are due to errors of observation, and are caused, for the most part, by variations in the strength of the inducing current. The mean values show exact equality.

It is thus proved that there is no inequality in the coefficients of increase and decrease of any such proportion as $3: 4$ or anything like it; but that for practical purposes we need only adnit one coefficient of change of magnetism produced by external forces, whether they tend to increase or to decrease it. This is, of course, true only within certain limits ; how far these limits extend must be left for further investigation. I will only remark here that, with forces which amount to about half of the earth's horizontal magnetism, more or less, we arrive practically at the same numbers.

It appears from these results that this subject has been invested with unnecessary difficulty. One other point, it is true, remains undecided, viz. the question whether, and under what circumstances, a change of the induced magnetic moment with time can be disregarded. Without doubt such an influence exists, but for magnets of hard steel it may no doubt be neglected in practice. 


\section{On the Determination of the Temperature Coefficient} of a Magnet.

The following general and sensitive method may be added to the known methods of W. Weber and Lamont. The bar to be examined is brought near to a reflecting magnetic needle in the horizontal plaue of the needle so that its centre point lies in the meridian of the needle, and so that it, acting together with the earth's magnetism, brings the needle into an east-andwest position. Let the bar in this position make an angle $\phi$ with the meridian. If now the magnetism $M$ of the bar change by an anount $\Delta M$, the needle will alter its position by the snall angle $\Delta \varepsilon$. Then, apart from corrections (compare below), it is easily seen that we have

$$
\frac{\mathrm{AM}}{\mathrm{M}}=\frac{1}{2} \tan \dot{\phi} \cdot \Delta \epsilon \text {. }
$$

We observe that this method may be made very sensitive by choosing the distance of the magnet from the needle so that the angle $\phi$ shall be small.

For the practical employment of this mothod it is very convenient to have the magnetic bar on the rotating arm of a graduated circle. As a magnetic needle I have employed a steel ciisk with reflecting surfaces. The method of procedure is then as follows:-

In order to measure the angle $\phi$, the magnetic bar is rotated from its original position until the image of tho scale is seen in the second reflecting surface. This rotation amounts then to $2 \phi$. The rotating arm in the two positions differing by $2 \phi$, is struck, and the magnet rotated in each observation between the strokes, $i$. $e$. when cold and when hot. The influence of small unintentional rotations of the magnetic axis of the bar, such as might be produced by the heating itself, is thus avoided.

Let $A$ be the distance of the scale from the mirror at the one temperature $t$. Let the positions $\epsilon_{1}$ and $\epsilon_{2}$ of the needle be observed upon rotation of the bar through the angle $2 \phi$, and at the other temperature $t^{\prime}$ the positions $\epsilon_{1}^{\prime}$ and $\epsilon_{2}^{\prime}$. If we denote $\epsilon_{1}-\epsilon_{2}$ by $n$ and $e_{x}^{\prime}-\epsilon_{2}^{\prime}$ by $n^{\prime}$, then the relative loss of magnetism,

$$
\frac{\Delta M}{M}=\frac{\tan \phi}{8 \mathrm{~A}}\left(n-n^{\prime}\right) ;
$$

and the temperature-coefficient therefore,

$$
\theta=\frac{\tan \phi\left(n-n^{\prime}\right)}{8 \mathrm{~A}\left(t-t^{\prime}\right)}
$$


Corrections for the Length of the Rod.-Tt would not be practicable to make the distance of the magnet from the needle so great that the length of the bar might be neglected; since for a considerable distance there would exist no angle $\phi$ which would bring the needle into a transverse position. We may take account of the length of the rod by multiplying the above result by

$$
1+\frac{1}{8} \frac{\lambda^{2}}{a^{2}}\left(3+5 \cos ^{2} \phi\right)
$$

In this $\alpha$ is the distance of the middle point of the magnet from the needle, $\lambda$ the distance apart of the poles of the magnet-that is, in the case of bar-magnets, five sixths of the length of the bar.

\section{On the Bifilar Determination of Moments of Inertia.}

Gauss's well-known method of determining the moment of inertia of a body from its oscillations, when loaded and in the unloaded condition, eliminates the unknown directive force of the oscillations. The employment of a known directive force (e.g. of a bifilar* directive force) permits the employment of a simpler method.

I was induced to investigate this method of determination by obtaining, by means of suspended weights, inconsistent measurements of the moment of inertia of a magnetic bar, and, in spite of the greatest care, a result too great, as could be concluded from geometrical measurement of the carefully worked bar.

The method was carried out by means of the bifilar-suspension arrangement recently described by met. We determine first the moment of inertia of the bifilarly-suspended carrier

* KohIrausch, Wied. Ann. xvii. p. 744 (1882).

$\dagger$ By adopting the extremely convenient method of M. Wild, in which the oblique surfaces over which the wires run are replaced by surfaces at right angles to which the wires are clamped (Rep.f. Meteor.d. K. Acad. d. Wiss. St. Petersb. vii. No. 7, 1883).

I may be allowed to remark here that I am quite unable to regard my method of the "bifilar" measurement of the earth's magnetic intensity as a combination of Gauss's method with that of Wild, as M. Wild appears to do (loc. cit. p. 2). I believe that I may claim for my method that it is an altogether independent one. For the "bifilar galvanic method" out of which the "bifilar magnetic" has been evolved, is found described, long before the first of the publications of M. Wild on this subject, and with account taken of the torsion of the threads, in the third edition of the Leitfaden der praktischen Physik, 1877, p. 184. The first bifilar-magnetic method described by Wild in the year $188 \mathrm{l}$ is, further, altogether different from mine both in arrangement and in object. Wild's second method is more nearly like mine, but it was unknown to me, siace it was published later than mine. 
by means of the well-known relation between the oscillationperiod $t$, the bifilar directive force, and the moment of inertia $\mathrm{K}=\frac{\mathrm{D} t^{2}}{\pi^{2}}$; then the body to be investigated is laid in the carrier, and the moment of inertia of both is determined in the same way.

I must refer to my former paper* for the method of determining the directive force $D$ from the distance apart, the length, weight, and elasticity of the suspension-threads, and the weight of the body, as well as for details of instrumental adjustment and observation.

If the body is magnetic, we have to eliminate from the bifilar direction-force tbat arising from the earth's magnetism with the relatively small magnitude of the latter. This is easily done by arranging that during the oscillations the magnet shall lie east and west. Or we may bring the suspension with the magnet into the meridian, and observe the oscillation-period $t_{1}$ in the normal position and $t_{2}$ in the reversed position of the magnet. Then the oscillation-period of the unmagnetized body would be

$$
\sqrt{ } 2 \frac{t_{1} t_{2}}{\sqrt{t_{1}^{2}+t_{2}^{2}}}
$$

Lastly, the measurement of moment of inertia may be made before the body is magnetized.

It is a matter of course that the requisite care should be bestowed upon the adjustment of the ceritre of gravityt.

The oscillations are performed generally very rapidly, much more so than one is accustomed to with swinging magnets. The observations, however, may be made with the same accuracy. We simply note the times of reversal on each side, in doing which we may, if necessary, omit one or more.

The accuracy which may be attained is not inferior to that which may be obtained with slower vibrations. I found the results of separate observations, when the oscillation-period amounted to about 1 second, to agree to within a few tenthousandths of a second.

The moments of inertia of the magnetic bar mentioned before ( 16 centim. long, $216 \mathrm{gr}$. weight) agreed very well with each other, as well as with that calculated from its dimensions.

The following may be mentioned as advantages of the bifilar mode of determination:-

* F. Kohlrausch, Wied. Ann. xvii. pp. $744 \& 745$ (1882).

$\dagger$ F. Kohlrausch, loc. cit. p. 754 . 


\section{Prof. Sylvester on Hamilton's Quadratic Equation}

(1) The avoiding of the principal errors of weights simply hung on*, or the uncertrinty resulting from the possible heterogeneous nature of solid bodies used as loads, as, for example, Lamont's ring.

(2) The avoiding of variations of a magnetic directive force by the temperature and terrestrial magnetic variations.

(3) The greater simplicity of repeating a determination by means of a single oscillation-period when the moment of inertia of suspension has been determined once for all.

(4) The avoiding of the influence of layers of air vibrating with the body, or of any possible magnetic induction upon the weights used as load.

L. On Hamilton's Quadratio Equation and the general Unilateral Equation in Matrices. By. J. J. SyLTESTER, F.R.S., Suvilian Professor of Geometry in the University of Oxford $\dagger^{\text {. }}$

N the Philosophical Magazine of May last I gave a purely 1 algebraical method of solving Hamilton's equation in Quaternions, but did not carry out the calculations to the full extent that I have since found is desirable. The completed solution presents some such very beautiful features, that I think no apology will be required for occupying a short space of the Magazine with a succinct account of it.

Hamilton was led to this equation as a means of calculating a continued fraction in quaternions, and there is every reason for believing that the Ganssian theory of Quadratic Forms in the theory of numbers may be extended to quaternions or binary matrices, in which case the properties of the equation with which I am abont to deal will form an essential part of such extended theorył. Let us take a form slightly more general than that before considered, viz. the form

$$
p x^{2}+q x+r=0,
$$

with the understanding that the determinant of $p$ (if we are dealing with matrices), or its tensor if with quaternions, differs

* Compare Dorn, Wied. Ann. xvii. p. 788 (1882), and O. Beling, 'On the Theory of Bifilar Suspension ' (Breslau, 1881).

$\dagger$ Communicated by the Author.

I I have found, and stated, I believe, in the form of a question in the 'Educational Times' some years ago, that any fraction whose terms are real integer quaternions may be expressed as a finite continued fraetion, the greatest-common-measure process being applicable to its two terms, provided $b$ ot $h$ their Moduli are not odd multiples of an odd power of 2 , which can always be guarded against by a previous preparation of the fraction. 